\title{
DOENÇA DE WHIPPLE APÓS TRANSPLANTE RENAL: RELATO DE CASO E REVISÃO DA LITERATURA
}

\author{
Post-kidney transplant Whipple's disease: a case report and literature review \\ Danielle Figueiredo da Cunha', Natalie Anderson Nasser', Olga Abrão Vieira', Carlos Frederico Ferreira Campos², \\ José Carlos Lino da Silva ${ }^{3}$, Tereza Azevedo Matuck', Deise De Boni Monteiro Carvalho ${ }^{1}$
}

\begin{abstract}
RESUMO
Após mais de cem anos da descrição da doença de Whipple por George H. Whipple, o diagnóstico, patogênese e tratamento ainda permanecem motivo de controvérsia. É decorrente da rara infecção pela bactéria Tropheryma whipplei, que também é encontrada no meio ambiente sem causar dano. Os sintomas são inespecíficos, tais como: diarréia, artralgia e inapetência, podendo apresentar graves sintomas cardíacos e no sistema nervoso central. O diagnóstico mais sensível é realizado através de PCR (reação em cadeia da polimerase) e imunohistoquímica, porém ainda pouco difundidos. O tratamento é realizado com ceftriaxone endovenoso seguido por sulfametoxazol-trimetoprima por dois anos. Abaixo, é descrito um caso de doença de Whipple após transplante renal, o qual os autores acreditam ser o segundo caso relatado na literatura.
\end{abstract}

Descritores: Transplante Renal, Doença de Whipple, Tropheryma whipplei.

\section{Instituição:}

1 Unidade de Transplante Renal do Hospital Federal de Bonsucesso - Rio de Janeiro/ RJ - Brasil

2 Unidade de Anatomia Patológica do Hospital Federal de Bonsucesso - Rio de Janeiro/ RJ - Brasil

3 Unidade de Endoscopia Digestiva do Hospital Federal de Bonsucesso - Rio de Janeiro/

RJ - Brasil

\section{Correspondência:}

Dra. Deise De Boni Monteiro Carvalho

Unidade de Transplante Renal do Hospital Federal de Bonsucesso

Avenida Londres, 616 - CEP: 21041-030-Rio de Janeiro/RJ Brasil

Fone: (21) 3977-9637

E-mail:deisebmc@gmail.com

\section{INTRODUÇÃO}

A doença de Whipple é uma afecção multissistêmica rara, que atinge principalmente homens caucasianos de meia idade, cursando com perda de peso, diarréia, artralgia e dor abdominal. Há uma variedade de órgãos que podem estar envolvidos na doença, como coração, pulmão e sistema nervoso central.

A doença foi inicialmente descrita por George H. Whipple em 1907, porém, apenas em 1961 foi possível sua correlação com um agente infeccioso, após visualização por microscopia eletrônica de macrófagos gigantes contendo inclusões semelhantes a corpos baciliformes positivos para coloração com ácido periódico de Schiff (PAS) e que corresponderiam a uma bactéria. ${ }^{1}$ A identificação em outros tecidos e líquidos (pericárdio, endocárdio, gânglios linfáticos, líquido sinovial, pulmão, cérebro e meninges) atesta sua natureza sistêmica.

Após utilização de técnicas de imunogenética, a partir de 1991, 
foi possível determinar a seqüência de $16 \mathrm{~S}$ rRNA, concluindo que se trata de um actinomiceto gram-positivo, nomeada Tropheryma whipplei. ${ }^{2}$ Mais recentemente, desenvolveu-se teste sorológico por imunoflorescência utilizando linhagem celular de fibroblastos humanos infectados pelo bacilo. Esse teste mostrou-se extremamente útil, uma vez que possibilitou o diagnóstico através do sangue periférico em doentes com complicações graves. ${ }^{3}$ Porém, a sorologia ainda não se encontra disponível, devido à ocorrência de reações cruzadas, mas o crescimento do organismo em meio acelular proporcionará a preparação de antígenos seletivos e também teste de sensibilidade aos antibióticos.

Alguns estudos tentam correlacionar o papel das alterações imunológicas encontradas em alguns doentes com a persistência do bacilo nos tecidos. O predomínio da doença em homens de meia-idade evidencia a maior suscetibilidade ao organismo causador, podendo demonstrar déficit de imunidade celular e/ou tolerância imune envolvidas com a ativação e predisposição da infecção pela T. whipplei. ${ }^{4}$

O tratamento proposto para doença de Whipple usa ceftriaxone endovenoso por no mínimo sete dias com êxito na maioria dos pacientes e manutenção com sulfametoxazol-trimetoprima por aproximadamente dois anos. Contudo, alguns doentes apresentam recidivas em meses ou anos após a suspensão do antibiótico e mesmo durante o tratamento, principalmente quando ocorre acometimento do sistema nervoso central. ${ }^{5}$

\section{CASO CLÍNICO}

Mulher, 36 anos, raça negra, casada, natural e residente no Rio de Janeiro, renal crônica devido à nefroesclerose hipertensiva, tendo iniciado hemodiálise em 2006. Sorologias HBs Ag negativo, antiHBs positivo (vacinação), anti-HCV negativo, anti-HIV negativo, citomegalovírus IgG positiva, toxoplasmose IgG e IgM negativas, VDRL negativo e doença de Chagas negativa. Aos 38 anos, em 04/11/2008, foi submetida a transplante renal doador vivo não relacionado (esposo) com seis mismatches e crossmatch para linfócito $\mathrm{T}$ e B negativos, reatividade contra painel negativa para classe I e II. Realizou indução com basiliximab $20 \mathrm{mg} /$ dia no dia do transplante e no quarto dia. Imunossupressão inicial com tacrolimus $0,2 \mathrm{mg} / \mathrm{kg} / \mathrm{dia}$, prednisona $30 \mathrm{mg} / \mathrm{dia}$ e micofenolato sódico $1440 \mathrm{mg} /$ dia. No quinto dia de pós-operatório apresentou aumento de peso e piora da função renal, com suspeita clínica de rejeição aguda. Não realizada biopsia de enxerto renal devido à recusa da paciente. Feito pulsoterapia com solumedrol $1 \mathrm{~g} /$ dia por três dias, porém, evoluiu com piora da função renal e diminuição da diurese, tendo sido realizada pulsoterapia mais três dias, com boa resposta. Recebeu alta no décimo quinto dia do transplante, com creatinina séria de $1,7 \mathrm{mg} / \mathrm{dL}$, uréia sérica de $66 \mathrm{mg} / \mathrm{dL}$, clearance de creatinina $54 \mathrm{ml} /$ min, boa diurese e peso de $77 \mathrm{~kg}$.

Após doze meses do transplante renal, em novembro de 2009, começou a apresentar queixas de anorexia, diarréia persistente aquosa, sem sangue ou muco, sem odor característico e perda ponderal significativa, evoluindo com fraqueza muscular e dor em ombros. Negava outros sintomas como febre, alterações cutâneas, sintomas respiratórios ou urinários.

Realizada investigação com exame de endoscopia digestiva alta, em fevereiro de 2010, apresentou esôfago e estomago sem alterações, duodeno com leve pontilhado brancacento e aspecto macroscópico sugestivo de doença de Whipple. Histopatológico evidenciou vilosidades duodenais englobando grupos de macrófagos, coloração especial com PAS revelou numerosos bacilos em citoplasma de macrófagos na lâmina própria, métodos de Fite, Wade, WarthinStarry e Giemsa negativos; confirmando a doença (Figuras 1 a 4). Diante desse resultado, foi iniciado sulfametoxazol-trimetoprima (400-80mg) duas vezes ao dia e a dose de tacrolimus foi progressivamente reduzida. Foram descartadas outras infecções intestinais e infecção por citomegalovírus.

Figura 1 - Fragmentos de mucosa duodenal exibindo vilosidades expandidas à custa de edema e infiltração de células inflamatórias na lâmina própria (hematoxilina e eosina, objt $\times 4$ ).

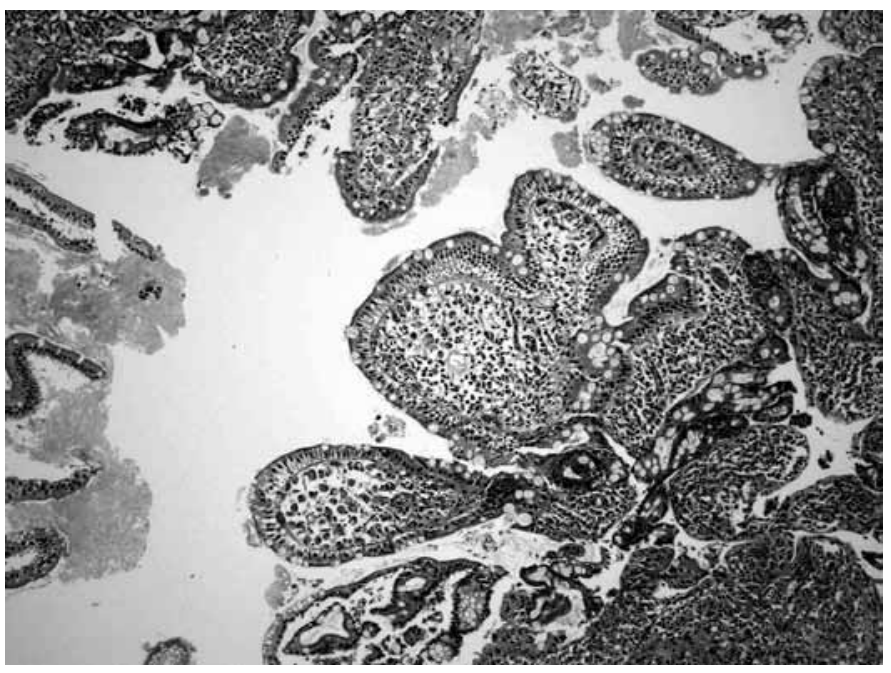

Figura 2 - Infiltrado inflamatório constituído predominantemente por macrófagos, com alguns linfócitos e plasmócitos de permeio (hematoxilina e eosina, objt $\times 40$ )

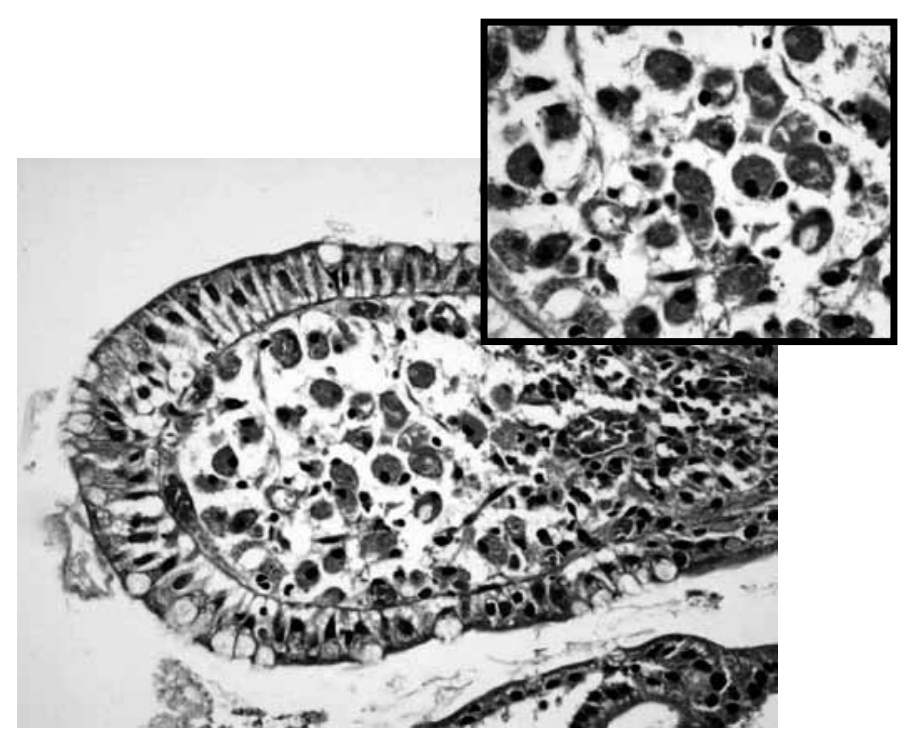


Figura 3: Histiócitos exibindo citoplasmas amplos, preenchidos por material granular (hematoxilina e eosina, objt x 100).

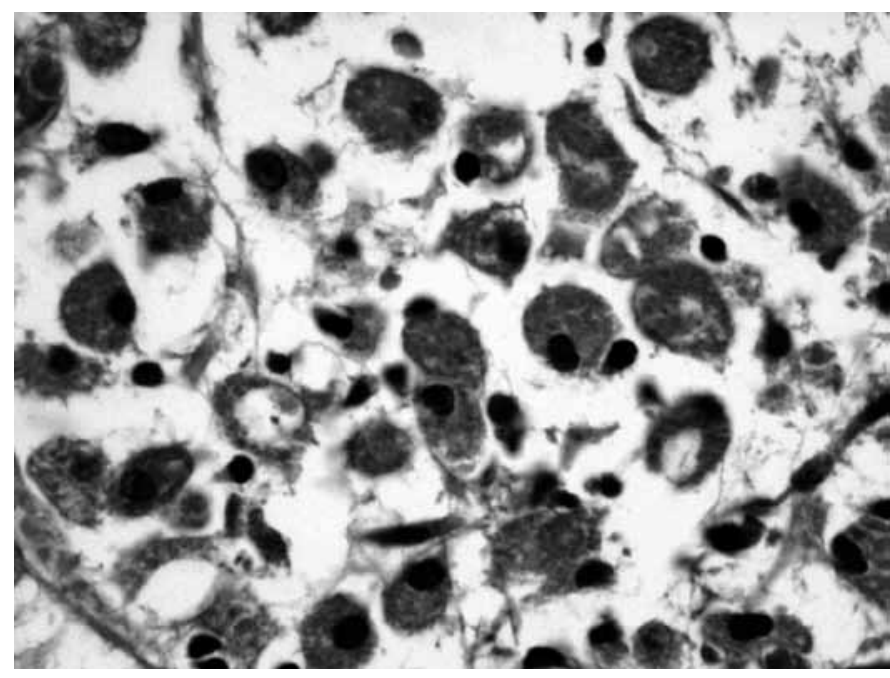

Apresentou piora da diarréia, dificuldade de deambulação, fraqueza muscular de membros superiores e inferiores, o que a impedia de realizar qualquer movimento e inapetência, sendo internada dia 20/02/2010. Ao exame físico: lúcida e orientada, emagrecida, tetraparética, ausência de rigidez de nuca e de qualquer alteração neurológica localizatória. Apresentava boa diurese, aumento de escórias nitrogenadas, com uréia sérica de $100 \mathrm{mg} / \mathrm{dL}$, creatinina sérica de $3,9 \mathrm{mg} / \mathrm{dL}$, potássio sérico de $1,9 \mathrm{mEq} / \mathrm{L}$, cálcio sérico de $8,2 \mathrm{mEq} / \mathrm{L}$, fósforo sérico de $3,2 \mathrm{mEq} / \mathrm{L}$ e magnésio de $1,0 \mathrm{mEq} / \mathrm{L}$. Realizada hidratação parenteral com reposição de potássio e magnésio. Iniciado ceftriaxone $1 \mathrm{~g}$ endovenoso duas vezes ao dia por sete dias.

Evoluiu com melhora progressiva da tetraparesia e da diarréia, com creatinina sérica de $1,4 \mathrm{mg} / \mathrm{dL}$, uréia sérica de $11 \mathrm{mg} / \mathrm{dL}$, potássio sérico de $3,9 \mathrm{mEq} / \mathrm{L}$ e magnésio $2,0 \mathrm{mEq} / \mathrm{L}$, nível sérico de tacrolimus $6,9 \mathrm{mcg}$. Recebeu alta após quinze dias de internação com sulfametoxazol-trimetoprima (400-80mg) duas vezes ao dia, prednisona $5 \mathrm{mg} / \mathrm{dia}$, tacrolimus de $8 \mathrm{mg} / \mathrm{dia}$ e micofenolato sódico $1440 \mathrm{mg} / \mathrm{dia}$, com boa tolerância às medicações. Manteve-se bem e em acompanhamento no ambulatório por seis meses e com proposta de manter o tratamento com sulfametoxazol-trimetropima (400-80mg) duas vezes ao dia por dois anos. Prevista nova endoscopia digestiva alta em um ano para nova biopsia e reavaliação do quadro.

\section{DISCUSSÃO}

A doença de Whipple pode manifestar-se com uma variedade de sintomas, incluindo: diarréia, má-absorção, dor abdominal, artralgia, febre, adenopatia e envolvimento do sistema nervoso central. Estudo retrospectivo de casos clínicos relatados na literatura médica analisou as manifestações clínicas mais comuns da doença: perda de peso $(93 \%)$, diarréia $(81 \%)$, artrite ou artralgia (73\%). ${ }^{6}$ Na maioria dos casos, a doença de Whipple instala-se de forma não específica, como oligo ou poliartrite soronegativa. No caso relatado, após doze meses do transplante renal, surgiram manifestações gastrointestinais e artralgia em ombro, sintomas muito prevalentes na doença de Whipple.
Postula-se que exista um defeito primário na imunidade celular que predispõe alguns indivíduos a desenvolverem a doença. ${ }^{7}$ A alteração celular ainda é desconhecida, porém, algumas séries de pacientes pesquisados apresentavam diminuição dos níveis de interleucina12 p40 e do fator de necrose tumoral alfa (TNF- $\alpha$ ). ${ }^{8}$ A exacerbação da doença já foi descrita com o uso do infliximab, sugerindo que o TNF- $\alpha$ tenha associação na patogênese. ${ }^{9}$ Outro estudo demonstrou que pacientes com artropatia e em uso de drogas imunomoduladoras podem desencadear a Doença de Whipple. ${ }^{10}$ A associação entre alteração da imunidade celular e a doença de Whipple explicaria a ocorrência em pacientes transplantados. Todavia, na revisão de literatura, foi encontrado apenas um caso descrito de transplante renal associado à doença de Whipple. ${ }^{11}$ A explicação talvez seja pelo fato de que a grande maioria dos pacientes transplantados utilizam sulfametoxazol-trimetoprima para profilaxia de Pneumocystis carinii durante o período de maior imunossupressão. Por outro lado, a doença de Whipple pode ser um defeito primário da função do macrófago, não sendo, portanto, afetado por uma alteração nas células $\mathrm{T}$, como acontece com pacientes transplantados e naqueles com imunodeficiência adquirida. ${ }^{12}$

Embora, tradicionalmente, a doença de Whipple seja diagnosticada pela histopatologia de duodeno, vários métodos como cultura, imunohistoquímica, pesquisa molecular estão disponíveis. $\mathrm{Na}$ histopatologia, que é o método mais comumente empregado para o diagnóstico, observam-se bacilos em citoplasma de macrófagos que se coram pelo PAS. A cultura da T. whipplei, que anteriormente era considerada uma "bactéria não cultivável", já se tornou possível em laboratórios especializados, porém, devido à demora de meses para o crescimento, dificilmente é aplicada em tempo real para decisão clínica. A imunohistoquímica confirma a histopatologia ao detectar os bacilos no tecido duodenal, nas válvulas cardíacas e em outros tecidos, com uso do anticorpo específico contra a T. whipple. Em um estudo, a imunohistoquímica confirmou o diagnóstico de doença de Whipple em paciente com histopatologia de duodeno com PAS negativo. ${ }^{13}$

A pesquisa molecular por PCR é um importante método diagnóstico. Realizada por mais de uma década, é considerada o método nãoinvasivo mais sensível, específico e rápido para o diagnóstico da doença de Whipple..$^{14}$ A pesquisa do PCR para T. whipplei é capaz de detectar o bacilo no sangue, no líquido sinovial, no líquor, no humor aquoso, de acordo com as manifestações clínicas da doença. Além disso, a pesquisa do PCR pode ser utilizada para monitorizar a resposta terapêutica e para detectar a não resposta, mesmo em uso do antibiótico adequado. ${ }^{15}$

Devido à rara ocorrência da doença de Whipple, nenhum estudo rigoroso foi realizado para determinar o melhor tratamento a ser utilizado. Vários antibióticos foram testados clinicamente e outros foram avaliados em laboratório, incluindo tetraciclinas (como a doxiciclina em combinação com hidroxicloroquina), penicilinas, estreptomicina e sulfametoxazol-trimetoprima. ${ }^{16} \mathrm{Em}$ alguns casos relatados, a recidiva da doença ocorre frequentemente com o uso de tetraciclina e raramente com sulfametoxazol-trimetoprima, ou com a combinação de penicilina e estreptomicina. ${ }^{17} \mathrm{Em}$ pacientes com acometimento do sistema nervoso central utiliza-se antibióticos que atravessem a barreira hematoencefálica, como o ceftriaxone, mantendo com sulfametoxazol-trimetoprima, por no mínimo, de um a dois anos. Porém, não há recomendações quanto ao tempo de tratamento em pacientes imunocomprometidos, como no caso 
de pacientes transplantados.

Em suma, este relato descreve o que acreditamos ser o segundo caso de doença de Whipple após transplante renal. Nossa paciente apresentou manifestações gastrointestinais, como diarréia, inapetência, vômitos e perda de peso típicas da doença, além de artralgia em ombro. O diagnóstico foi realizado através da biopsia de duodeno, mostrando macrófagos corados pelo PAS. A paciente recebeu tratamento com ceftriaxone endovenoso por sete dias continuando com sulfametoxazol-trimetoprima, com melhora importante dos sintomas.

\section{ABSTRACT}

After more than one hundred years of the description on the Whipple's disease by George H. Whipple, the diagnosis, pathogenesis and treatment still remain controversial. It is rare disease caused by the Tropheryma whipplei bacterium, which is also found in the environment without causing any damage. Symptoms are nonspecific, such as diarrhea, arthralgia, and weakness; it may present severe cardiac symptoms and in the central nervous system. The most accurate diagnosis is performed by PCR (polymerase chain reaction) and immunohistochemistry, but they are poorly disseminated. Treatment is with intravenous ceftriaxone followed by trimethoprim-sulfamethoxazole for two years. Below, this article describes a case of Whipple's disease after renal transplantation, which the authors believe to be the second case reported in literature.

Keywords: Kidney transplantation, Whipple Disease, Tropheryma whipplei.

\section{REFERÊNCIAS}

1. Yardley JH, Hendrix TR. Combined electron and light microscopy in Whipple's disease: demonstration of 'bacillary bodies' in the intestine. Bull Johns Hopkins Hosp. 1961;109:80-98.

2. Wilson KH, Blitchington R, Frothingham R, Wilson JA. Phylogeny of the Whipple'sdisease-associated bacterium. Lancet. 1991;338:474-5.

3. Raoult D, Birg ML, La Scola B, et al. Cultivation of the bacillus of Whipple's disease. N Engl J Med. 2000;342:620-5.

4. Marth T, Kleen N, Stallmach A, et al. Dysregulated peripheral and mucosal Th1/ Th2 response in Whipple's disease. Gastroenterology. 2002;123:1468-77.

5. Feurle GE, Marth T. An evaluation of antimicrobial treatment for Whipple's disease: tetracycline versus trimethoprim-sulfamethoxazole. Dig Dis Sci. 1994;39:1642-8.

6. Fenollar F, Puechal X, Raoult D.Whipple's disease. N Engl J Med. 2007;356:55-66.

7. Benoit M, Fenollar F, Raoult D, Mege JL. Increased levels of circulating IL-16 and apoptosis markers are related to the activity of Whipple's disease. PLoS ONE. 2007;2:494.

8. Kalt A, Schneider T, Ring S, et al. Decreased levels of interleukin-12p40 in the serum of patients with Whipple's disease. Int J Colorectal Dis. 2006;21:114-20.

9. Kneitz C, Suerbaum S, Beer M, Müller J, Jahns R, Tony HP. Exacerbation of Whipple's disease associated with infliximab treatment. Scand J Rheumatol. 2005;34:148-51.

10. Mahnel R, Kalt A, Ring S, Stallmach A, Strober W, Marth T. Immunosuppressive therapy in Whipple's disease patients is associated with the appearance of gastrointestinal manifestations. Am J Gastroenterol. 2005;100:1167-73.

11. Razonable JS, Pulido PJ, Deziel S, Dev DR. Chorioretinitis and vitreitis due to Tropheryma whipplei after transplantation: case report and review. Transpl Infect Dis. 2008:10:413-8.

12. Desnues B, Ihrig M, Raoult D, Mege JL. Whipple's disease: a macrophage disease. Clin Vaccine Immunol. 2006;13:170-8.

13. Baisden BL, Lepidi H, Raoult D, Argani P,Yardley JH, Dummler JS. Diagnosis of Whipple disease by immunohistochemical analysis: a sensitive and specific method for the detection of Tropheryma whipplei (the Whipple bacillus) in paraffin-embedded tissue. Am J Clin Pathol. 2002;118:742-8.

14. Fenollar F, Raoult D. Molecular techniques in Whipple's disease. Expert Rev Mol Diagn. 2001;1:299-309.

15. Brühlmann $\mathrm{P}$, Michel BA, Altwegg $\mathrm{M}$. Diagnosis and therapy monitoring of Whipple's arthritis by polymerase chain reaction. Rheumatology (Oxford). 2000;39:1427-8.

16. Boulos A, Rolain JM, Mallet MN, Raoult D. Molecular evaluation of antibiotic susceptibility of Tropheryma whipplei in axenic medium. J Antimicrob Chemother. 2005;55:178-81.

17. Feurle GE, Maiwald M, Marth T. Randomized controlled trial of antimicrobial treatment in Whipple's disease. Gastroenterology. 2007;132:A639. 